\section{African \& Caribbean Dental Association UK}

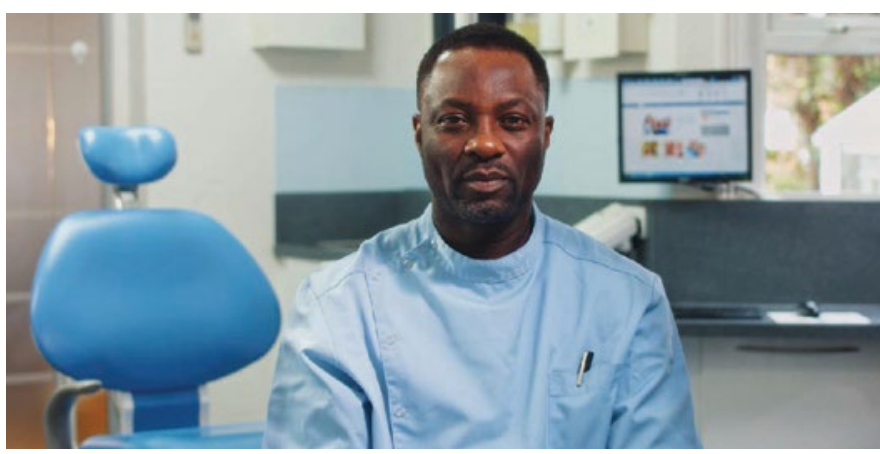

Dr Timi Adesanya, Chair of ACDA-UK

\section{W}

ho founded the society and why?

The African \& Caribbean Dental Association UK

(ACDA-UK) is a registered charity and was formed by

Dr Julius Babayemi and Dr Timi Adesanya (current chair, pictured) in response to a demand for better oral health awareness amongst minority groups in the UK.

It was also set up to provide a platform for like-minded dental professionals of African and Caribbean ethnic origin to share experience, learn from each other and give something back to their local communities.

Another reason the association was formed was to inspire the next generation through mentoring and providing positive role models.

\section{How many members are there and how do you become one?} We have about 230 people in the group (dentists, dental nurses, dental technicians, dental therapists and hygienists, and students); the membership levels are Dentist, Dental care professional and Student.

To become a member you can send an email to info@acda-uk.org requesting to be a member.

\section{What are the aims of the society?}

- To promote equality, diversity and inclusion in oral health amongst ethnic minority groups, especially within the African and Caribbean communities in the UK

- To professionally and personally develop our members

- To advance education, particularly amongst young people to develop their capacity and skills, enabling them to participate fully in society.

\section{What services do you provide your members?}

- Mentoring and career advice for students and young professionals in the group

- Job opportunities

- Networking opportunities - access to local, national and international peers

- Discussing clinical cases and providing clinical advice

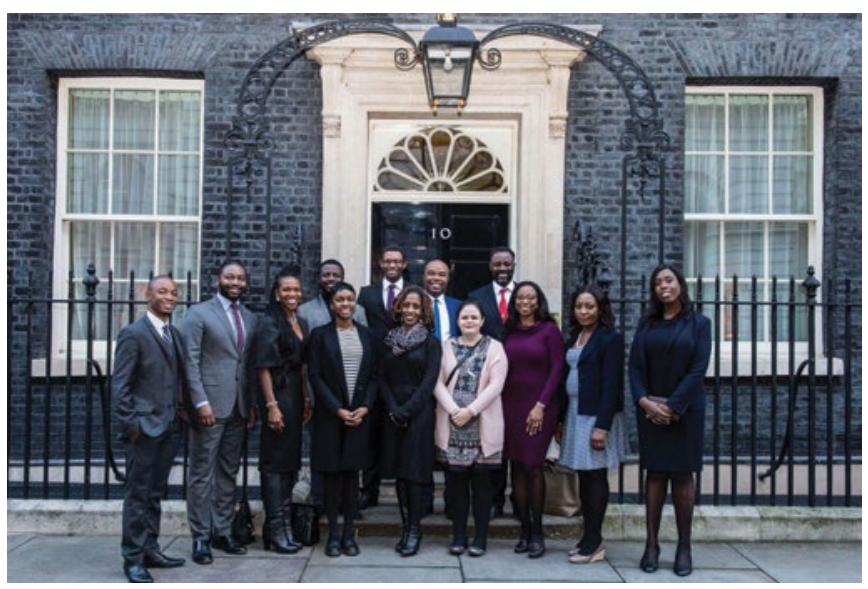

- Discounted CPD events, discounts on Association charity/social events

- Opportunities to group buy services and products from dental companies

- Opportunities to join ACDA-UK community Outreach Programme

- Help students with work placements/experience, with personal statements for those applying to dental school

- Help with practice purchases.

\section{What are the society's greatest achievements?}

A visit to 10 Downing Street to have a meeting with a Special Advisor to the Prime Minister (Theresa May) on social justice, young people and opportunities to discuss equality and diversity issues, barriers to young black people and how the association could be involved to address inequalities that black people may face in the profession and access to oral healthcare (see photo).

What does the society have planned for the next couple of years? We want to increase our membership and be more visible to the public. We want to continue to promote equality, diversity and inclusion in oral health, especially amongst the African and Caribbean ethnic group.

We want to engage dental institutions to understand how admission processes works and to influence them so they can increase their quota of admissions of students from African and Caribbean ethnic groups, especially in dental schools.

We would like to work closely with the BDA and FGDP(UK) on equality, diversity and inclusion issues in the profession.

\section{ACDA Scholarship Essay Award}

The ACDA Scholarship Fund is offering three students aspiring to work in the dental field the opportunity to win one of three prizes: 1 st prize $£ 500$ (personal Chairman donation); 2nd prize $£ 250$ (a donation from Imaging Technologies Ltd); and 3rd prize $£ 100$. Winners will receive vouchers to be used towards dental equipment/a subscription of their choice. To enter, students must write 500 words on the subject 'The dental professional I plan to become, how I will make my mark'. The deadline for entries is 15 January 2021. For more information, follow ACDA-UK on Instagram, @acda_uk.

For more information on ACDA-UK visit https://acda-uk.org/, call 08450509687 or email info@acda-uk.org. 